Schreiben des Herrn Prof. Dr. Argelander, Directors der Sternwarte in Bonn, an den Herausgeber.

In der ehen angelanglen 121695 hespricht Herr Profesgor C. H.F. Peters das Object, welches in unserer Durchnusterung in $-0^{\circ}$. M2 2436 ohne Grössenbezeichnung, auf den Bonner Himmelskarten als Nebelfleck verzeichnet ist. Mit demselben verhält es sich folgendermassen: im Cometensucher ist dieser Gegenstand $n$ icht gesehen vorden; da aber auf BogusLamski's Berliner Karte ein Nebelfleck in ungefähr $11^{\text {h }} 11^{\text {" }} 30^{\prime}$ $-0^{\circ} 25^{\prime}$ (Position 1855) verzeichnet sich vorfand, dessen Lage nahe mit dem Nebel h. $879=$ H. IV. 4 ubereinstimmte, so suchte ich 1856 März 23 diese Gegend am Meridiankreise auf, und beobachtete ein Object an zwei gut uhereinstimnden Fäden, aber zweifelhaft an einem Microscop für Declination. Unmittelbar vorher hatte ich den Nebel D. M. $+13^{\circ} .2386$ beobachtet, und als Nebel bezeichnet, unter diesen Nehel för unser Object einen Strich gemacht. Diesen Strich deutete ich nur als eine Wiederholung des Nebels der vorderen Zeile, und trug demgemäss das fragliche Object als Nebel in das Verzeichniss ein. Später durcb Schmidt's und d'Arrest's Bemerkungen in den Astronomischen Nachrichten Band 57, pag. 245 und 345 auf die Schwäche des Nehels aufmerksam gemacht, untersuchte Krïger diese Gegend 1862 Mai 18 am Heliometer und konote bei nicht ganz durchsichtiger Luft den Nebel nicht mit voller Sicherheit erkennen. Ich vermuthete daher, und glauhe es nach der Bemerkung von Herrn Prof, Peters jetzt mit Sicherbeit, dass ich nicht den Nebel, soulern den Stern beobachtet hahe, den Schmidt mit $\boldsymbol{x}$ bezeichnet. Zwar glauht Schmidt, dass dieser Stern im Meridiankreise nicht gesehen werden konne; ich muss aber dagegen benerken, dass ich damals auf die Beobachtung lichtschwacher Sterne sehr eingeübt war. Ich erlaube mir ubrigens, was die in unserer Durchnusterung vorkommenden Nebel hetrifft, auf Schönfeld's Aufsatz in den Astron. Nachr. Bd. 58, pag. 355 aufmerksam zu machen.

$$
\text { Bon n, } 1868 \text { Mai } 29 .
$$

\title{
Verkäufliche Fernröhre.
}

Zn verkaufen aus dem Nachlasse eines Dilettanten.

Ein Telescop von Michael Bader in München mit Objectiv von 48 Linien Oeffnung und 60 Zoll Brennweite, 2 terrestrischen und 5 astrononischen Ocularen, 2 Sonnengläsern, Cometensucher, Horizontal- unil Verticalkreis, auf Stativ nit freier Bewegung. Einkaufspreis $800 \mathrm{f}$. Forderung 25 Louisd'or.
Ein astronomischer Universalkreis von 8 Zoll Durchnesser, auf 10 Secunden ahlesbar, mit rechtwinkelig gebrnchenem Fernrohr von 13 Linien Oeffnung und 12 Zoll Brennweite. Beschrieben in Jahn's "Unterbaltungen in Gebiete der Astronomie etc." Jahrgang 1856. To 21. Dio Theilung des Kreises von Breithaupt $\mathscr{g}$ Sohn in Cassel. Einkaufepreis 200 Thlr. Forderung 10 Louisd'or.

Bremen. B. Alterwall Ja $10 F$.

Berichtigungen zu $\sqrt{ } 1673-1676$ der Astronomischen Nachrichten.

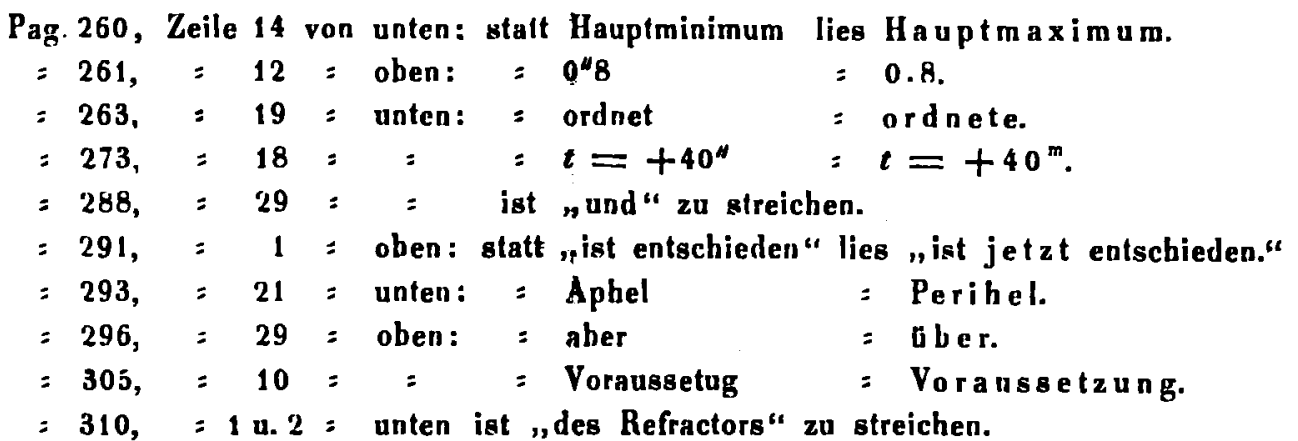

I $\mathrm{n} \mathrm{h}$ a $\mathbf{l} \mathrm{t}$.

(Zu Y 1698.) Beobachtungen von kleinen Planeten auf der Sternwarte zu Lund. Mitgetheilt von Herrn Director, Prof. Dr. Axel Möller. 273. On Erato. By E. Schubert. (Communicated by Prnf. J. H. C. Cuffin, Superintendent of the American Nautical Almanac.) 283. Schreiben des Herru Professors Dr. Argelander, Directors der Sternwarte in Bonn, an den Herausgeber. 287. Verkảufliche Fernröbre. 207. - Berichtigungen zu ô 1673 - 1676 der Astronomischea Nachrichien. 287. - 